within primary care, community and new-built modern hospital facilities. He passed his MRCPsych in 1956 and was elected FRCPsych in 1976.

In 1974, John made the leap from service leadership to international advisor. For 2 years he was Principal Medical Officer in Mental Health at the Scottish Home and Health Department and was then appointed advisor to the World Health Organization's (WHO) South-East Asia Office, based in New Delhi, where he and his wife Toshie lived for 4 years. They returned to the WHO's European Office in Copenhagen for 5 years, before John became Medical Director of St Andrew's Hospital, Northampton, where he remained until his clinical retirement in 1993.

Throughout his travels, John worked tirelessly to bring community, professional and political leaders together to improve the lot of people with mental health problems, and took courageous stands against the worst excesses of institutional abuse in the countries of the old Soviet bloc in Eastern Europe and on the notorious Greek island of Leros. His diplomatic skills, his persuasiveness from the public platform and the bravery he showed when all else failed are legendary among his fellow battlers. In between times, he and his wife welcomed with open arms all who managed to reach them in whatever corner of the world they were living.

Not surprisingly, John was never going to take easily to retirement and he was soon dedicating himself to a pan-European strategy for mental health, as President of the European Council of the World Federation of Mental Health and as a founder member and Policy Advisor to Mental Health Europe, the largest non-governmental organisation for mental health on the continent. I have vivid memories of the dramatic speech he delivered to the Ministerial Conference in 2005 and of his quieter attempts to lead the Royal College of Psychiatrists, Ariadne-like, in and out of the Minotaur's lair in Brussels. The fact that both were ultimately rebuffed did not deter him in the slightest. Not for nothing was his middle name Hope.

John retreated at the last to the shelter of his devoted family, to Toshie, his wife of 52 years, his four sons, two of whom had followed him into mental health, his ten grandchildren and two step-grandchildren, and to the friends, colleagues and admirers he had gathered around him over the years. He was a rugby player and referee of distinction, a skilled mountaineer who had climbed with some of Scotland's best from his earliest days in the Lairig Mountaineering Club, a regular skier from his chalet in the Pyrenees, a gardener, a wine buff, and a cook of passionate if sometimes anarchic technique.

Above all, John was a wonderful companion - whether you were floating down some foreign river on a tide of wine and anecdotes or sharing a bottle of whisky and a mutual contempt for bureaucracy around his fireside in Haddington. He was what we would call in Wales a simply 'lovely' man warm, generous, wise and loyal. I have no idea whether he was tall or not, but he always seemed so. When his spare frame came into view, everything seemed a little brighter and more possible. He died on 4 January 2010.

I promised to write to The Psychiatrist after your call, John. Instead, I find myself writing this obituary, and raising a glass or three in your memory. We shall miss you dearly.

Mike Shooter

doi: 10.1192/pb.bp.110.029918

\section{Dr Martin M. Whittet, OBE, MB.Ch.B., MB ChB, DPM, FRCP (Ed. and Glas.), FRCPsych, JP.}

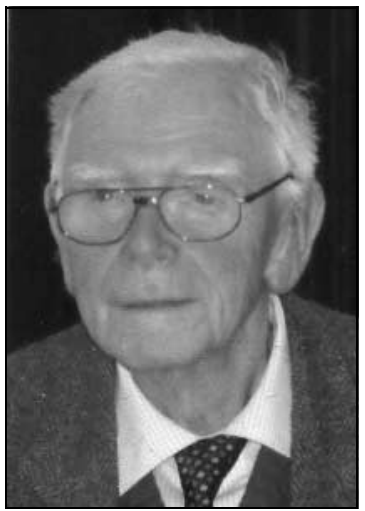

Martin Whittet was born in Glasgow on 12 November 1918. Both his parents were teachers. His secondary education was at Glasgow High School, where his father taught art. In 1942 he graduated from Glasgow University Medical School and moved on to pre-registration posts at Glasgow Royal Infirmary. After full registration he was appointed, in 1943, to Glasgow Royal Mental Hospital, rising to the post of Deputy

Physician Superintendent. In 1951, aged 33, he became Physician Superintendent at Craig Dunain Hospital, Inverness, responsible for mental healthcare in the Highlands and Islands, at which time he was the youngest doctor ever appointed to such a post. He set about modernising his hospital and changing public attitudes to mental health. To further this aim, he travelled widely in the Highlands, giving lectures to the lay public by invitation. His special interests were in alcoholism, depression, psychosexual problems and forensic psychiatry. $\mathrm{He}$ was a major contributor to the medical literature in his own field of psychiatry and published several books of interest to the public at large.

His contribution to medicine was recognised by the award of OBE in 1973. He initiated and was a lifelong strong supporter of Alcoholics Anonymous in the Highlands. Nationally, he was a Government Psychiatric Advisor to Scotland and Psychiatric Consultant to HM armed forces and HM prisons. His post demanded an appreciable amount of travelling, often by motor car, for which he had a driver who was the Craig Dunain farm lorry driver. I was duly impressed by this unusual member of his team, who was good company for many a mile, since Martin himself was not keen about driving. After retirement he passed this chore onto his wife to whom he also passed on much advice from the passenger seat.

Craig Dunain, when Martin arrived there, had a farm and a large pond in a tree-sheltered area of the grounds. When he left at retirement the hospital had an ornamental pool with ducks and other waterfowl, a soccer pitch, tennis courts, a nine-hole golf course, and a bowling green. His kindness, care and humanity were outstanding. There was always a coin or two in his pocket for children he met, and always a dog biscuit too for his dog friends. He retired in 1983 and pursued golf, fishing and the cultures of Gaeldom, including music, even learning Gaelic. In addition to direct clinical practice, he still 
read his $B M J$ and publications from the Colleges to which he belonged. He even found time to help out the St Andrew's Ambulance Association by examining aspirant first-aiders for their proficiency badge. Martin was also a Knight of Grace in the Grand Commandery of Lochore, of the Order of St Lazarus of Jerusalem.

He was an avid reader, consuming several newspapers a day. He was also an excellent raconteur. His love affair with the telephone was well known to many of his friends and colleagues. He loved the outdoor life, particularly in Wester
Ross-Shire and in the Borders, where he had numerous friends. He was a sincere animal lover, happy when walking his devoted dogs, but he was never happier than when Scotland won a rugby international. His contribution to the Highlands and Scotland will not be forgotten. He died on 10 December 2009 and is survived by his wife of 62 married years, a daughter, three sons, and eight grandchildren.

Murdoch W. Maclean

doi: 10.1192/pb.bp.110.030999 